\title{
Compassionate care: constitution, culture or coping?
}

\author{
Elaine Maxwell
}

School of Health and Social Care, London South Bank University, London, UK

\section{Correspondence to} Dr Elaine Maxwell, School of Health and Social Care, South Bank University, London, UK; maxwele2@|sbu.ac.uk

Accepted 5 September 2017 Published Online First 19 September 2017

\section{Linked}

- http://dx.doi.org/10.1136/ bmjqs-2017-006702

CrossMark

To cite: Maxwell E. BMJ Qual Saf 2017:26:947-948.
Alongside concern about avoidable mortality, one of the key findings of the public enquiry into failings at Mid Staffordshire NHS Foundation Trust, ${ }^{1}$ which ran Stafford Hospital in England, was the lack of compassion in care delivery. Sir Robert Francis, who led the enquiry, laid the blame for the compassion deficit at the door nursing and support staff. He recommended, among other things, that people should work as care assistants prior to nurse training and that values-based recruitment should be used to ensure that the 'right' people are recruited to be nurses. However, there has been little evidence to support these propositions. For example Snowden et $a l^{2}$ found that nursing students who had previous care jobs scored no higher for emotional intelligence than those without prior experience.

More recently opinion has shifted to the impact of compassionate leadership ${ }^{3}$ and compassionate environments on team behaviours. This move in part reflects the definition of culture as the shared assumptions that are normalised and are therefore absorbed by new staff as the correct way to think and behave. ${ }^{4}$ In this issue of BMJ Quality and Safety, Bridges and colleagues ${ }^{5}$ describe an intervention to develop the workplace at ward level through the use of a structured approach to creating learning environments for compassionate care (CLECC). The intervention uses reflection and group activities, including mid-shift cluster discussions to reinforce a team climate of compassion with a view to increasing the compassionate behaviours of individual members of the team.

Bridges et al used normalisation process theory $^{6}$ to evaluate the implementation of CLECC. They conclude that staff found it coherent and valued the principles. However, for some ward staff it remained a series of activities that they could articulate but had not become part of the shared assumptions of the ward. New starters were not socialised in its principles. Ownership of the intervention was variable: in some wards it was located outside the team and resided with practice development nurses. The authors suggest that the extent to which the intervention was faithfully implemented and normalised within individual wards was mediated by its relationship to the wider organisational agenda.

The partial implementation of an intervention is a common problem. In this case, the researchers observed a mismatch with organisational imperatives, perhaps indicating a lack of alignment between the priorities of the executive, the middle managers and the front-line staff. ${ }^{7}$ For managers, the drive for increased patient flow and cost efficiencies may be paramount, meaning that taking time out for reflection can appear to be counter cultural. This was illustrated by the manager described in this study who asked why staff were standing and drinking in the corridor: they were, in fact, undertaking a mid-shift cluster discussion.

The difference in priorities and therefore lack of apparent organisational support may well be part of the reason the intervention was not fully imbedded, but is it the whole story? Compassion is sometimes thought of as a fundamental human trait. But Benner and Wrubel ${ }^{8}$ assert that caring for strangers is significantly different from caring for friends and family. Professional caring involves emotional labour, which Hochschild ${ }^{9}$ defines as the induction or suppression of a feeling in order to produce in other people a sense of being cared for in a safe place. At times, this kind of labour can be overwhelming; staff can become stressed and less able to induce or suppress their feelings, and may avoid situations that require this behaviour. Isabel Menzies 
Lyth's ${ }^{10}$ classic work in 1960 showed how nurses organised their work to reduce emotional labour by splitting contact with patients into tasks in a way that is often seen as the antithesis of compassionate care.

In the 21st century, person-centred care is widely espoused. But when emotional labour becomes unsustainable, a task orientation may become dominant. Ball et al's ${ }^{11}$ study of English hospital wards found that $86 \%$ of nurses reported missed care on their last shift. They found a striking difference in the nature of what was missed; most commonly it was comfort/talking with patients (66\%) and educating patients (52\%), whereas the least likely to be missed were tasks such as pain management $(7 \%)$ and treatment and procedures $(11 \%)$. The fact that the nurses reported the care as missed implies insight into the needs of their patients for compassionate care. Both Ball and the authors of this paper propose that the omission is due to lack of staff time to undertake relational care; certainly, compassionate behaviours are not factored into calculations of staffing requirement. But this does not explain why two members of staff facing the same workload, within the same workplace climate, may behave differently. The answers may lie in a positive working environment and support for reflective practice that can help staff manage their emotional labour. ${ }^{12}$

Bridges et al showed that where the CLECC intervention was successfully implemented, there was an increase in staff morale and staff well-being. However, participating in CLECC involved talking about missed care, and it may be the case that the wards in this study which did not fully adopt CLECC were those in which staff were aware that they were omitting activities related to compassion. Rather than a lack of time or an unsupportive culture, nurses on these wards may have been actively managing their own well-being and avoiding cognitive dissonance by opting out of the intervention.

While personal agency cannot be the only explanation for lapses in compassion, it would be wrong to discount it. CLECC addressed the environmental conditions that facilitate compassion, and the challenge for implementing it further will be to integrate it with other factors including the management of individual emotional labour.
Twitter@maxwele2

Competing interests None declared.

Provenance and peer review Commissioned; internally peer reviewed.

(C) Article author(s) (or their employer(s) unless otherwise stated in the text of the article) 2017. All rights reserved.

No commercial use is permitted unless otherwise expressly granted.

\section{REFERENCES}

1 Francis R. Report of the mid staffordshire NHS foundation trust public inquiry: executive summary. London: The Stationery Office, 2013.

2 Snowden A, Stenhouse R, Young J, et al. The relationship between emotional intelligence, previous caring experience and mindfulness in student nurses and midwives: a cross sectional analysis. Nurse Educ Today 2015;35:152-8.

3 West M, Eckert R, Collins B. Caring to change: how compassionate leadership can stimulate innovation in health care. London: The King's Fund, 2017. https://www. kingsfund. org. uk/sites/files/kf/field/field_publication_file/Caring_to_ change_Kings_Fund_May_2017.pdf (accessed 20 Aug 2017).

4 Schein EH. Organizational culture and leadership. 4th edn. San Francisco, CA: Jossey-Bass, 2010.

5 Bridges J, May C, Fuller A, et al. Organising impact and sustainability: a qualitative process evaluation of a complex intervention targeted at compassionate care. BMJ Qual Saf 2017;26:970-7.

6 May C, Finch T. Implementing, embedding, and integrating practices: An outline of normalization process theory. Sociology 2009;43:535-54.

7 Schein EH. Three cultures of management: The key to organizational learning. Sloan Manage Rev 1996;38:9-20.

8 Benner P, Wrubel J. The primacy of caring: Stress and coping in health and illness. Reading, MA: Addison-Wesley/AddisonWesley Longman, 1989.

9 Hochschild A. The Managed Heart. Berkeley: University of California Press, 1983.

10 Menzies IEP. A case in the functioning of social systems as a defence against anxiety: a report on a study of the nursing service of a general hospital. Human Relations 1960;13:95-121.

11 Ball JE, Murrells T, Rafferty AM, et al. 'Care left undone' during nursing shifts: associations with workload and perceived quality of care. BMJ Qual Saf 2014;23:116-25.

12 Brunero S, Stein-Parbury J. The effectiveness of clinical supervision in nursing: an evidenced based literature review. Aust J Adv Nurs 2008;25:86-94. 